Jurnal Ilmu-Ilmu Peternakan 26 (3): 14 - 19

ISSN: 0852-3581

E-ISSN: 9772443D76DD3

OFakultas Peternakan UB, http://jiip.ub.ac.id/

\title{
Keberhasilan inseminasi buatan menggunakan semen beku dan semen cair pada sapi Peranakan Ongole
}

\author{
Trinil Susilawati, Nurul Isnaini, Aulia Puspita Anugra Yekti, Ika Nurjanah, Errico dan \\ Nolasco da costa
}

Fakultas Peternakan, Universitas Brawijaya, Malang

Jl. Veteran Malang 65145 Jawa Timur

trinil_susilawati@yahoo.com

\begin{abstract}
The purpose of this research was to know about the successfully artificial insemination (AI) using frozen and liquid semen of Ongole cross (PO) cattle indicated by Service per Conception (S/C), Days Open (DO) dan Conception Rate (CR). The materials used were 60 heads of Ongole crossbred cattle which were selected purposively using some criteria, such as having calving experience, healthy, and free from any reproduction disorder. This field experiment consisted of direct observation and interview to acquire primary and secondary data. Datas were analyzed descriptively and continued by a paired t-test. The results showed that the value of $(\mathrm{S} / \mathrm{C})$ was very significantly different $(\mathrm{P}<0.01)$, DO was not significantly different $(\mathrm{P}>0.05)$. CR for $\mathrm{P} 1, \mathrm{P} 2, \mathrm{P} 3$, and $\mathrm{P} 4$ was found $63.33 \%, 86.67 \%$, $16.33 \%, 83.33 \%$ respectively. The conclusion of this research was AI using frozen and liquid semen with only 5 days preservation had a difference on the value of service per conception. The most successfull AI was found higher in the liquid semen which was stored for 1 and 5 days than that of frozen semen.
\end{abstract}

Key words : semen, service per conception, days open, calving interval

\section{PENDAHULUAN}

Populasi penduduk di Indonesia semakin meningkat seiring dengan peningkatan pendapatan masyarakat, hal tersebut menyebabkan konsumsi daging sapi cenderung meningkat. Pemenuhan daging dalam negeri akan terus terhambat bila terjadi kekurangan sapi bakalan yang akan digemukkan dan sering terjadinya pemotongan sapi betina produktif, sehingga mengakibatkan populasi sapi di Indonesia mengalami penurunan. Salah satu wilayah produksi sapi pedaging terbesar di Indonesia adalah Jawa Timur yaitu sebanyak 4,7 juta ekor atau 31,89\% dari total populasi sapi pedaging di Indonesia (Kementerian Pertanian, 2011). Populasi sebanyak itu belum mampu mencukupi kebutuhan konsumen, sehingga antisipasi yang dilakukaan pemerintah adalah impor daging dan impor bakalan untuk digemukkan (Direktorat Jenderal Peternakan, 2007). Selain impor daging dan sapi bakalan, usaha produktivitas sapi pedaging sampai saat ini masih terus dikembangkan, baik dari segi produksi daging, kualitas daging dan perbaikan reproduksi ternak, namun kenyataannya masih belum optimal. Cara untuk mempercepat peningkatan populasi sapi pedaging dengan mengoptimalkan teknologi IB. Susilawati (2013) menyatakan bahwa IB telah terbukti memberikan dampak positif pada peningkatan populasi ternak. Program IB merupakan salah satu teknologi reproduksi 
yang mampu dan telah berhasil meningkatkan perbaikan mutu genetik ternak.

Program IB pada umumnya dilakukan menggunakan semen beku. Namun, penggunaan semen beku menghadapi beberapa masalah yaitu kurang lebih 30\% spermatozoa mati selama pembekuan dan spermatozoa yang bertahan hidup selama pembekuan mempunyai fertilitas rendah. Selain itu, harga nitrogen cair yang cukup mahal, sehingga penggunaan semen menghasilkan persentase kebuntingan yang lebih rendah. Situmorang (2002) menyatakan bahwa teknologi penggunaan semen cair yang digunakan sebagai pengganti semen beku dianggap lebih sederhana dan lebih baik. Hal ini terlihat pada penggunaan semen cair menghasilkan tingkat kebuntingan yang lebih tinggi.

Faktor keberhasilan IB dipengaruhi oleh kualitas semen, reproduksi ternak, keterampilan teknis inseminator dan deteksi birahi oleh peternak. Oleh karena itu, penelitian ini bertujuan untuk mengetahui keberhasilan inseminasi buatan menggunakan semen beku dan semen cair pada sapi Peranakan Ongole.

\section{MATERI DAN METODE}

\section{Lokasi dan waktu penelitian}

Penelitian ini dilakukan pada tanggal 26 September 2015 hingga 4 Februari 2016 di Loka Penelitian Grati Pasuruan untuk pengenceran semen dan pengaplikasian semen cair dilaksanakan di 4 desa yaitu Dandang Gendis, Sumber Anyar, Sidarum dan Plosari, Kecamatan Nguling, Kabupaten Pasuruan, Jawa Timur.

\section{Materi}

Materi yang digunakan dalam penelitian ini 60 ekor sapi indukan PO (30 ekor di IB dengan semen cair lama simpan 1 hari dan 30 ekor di IB dengan semen cair lama simpan 5 hari) dengan kriteria sudah pernah melahirkan, sehat, bebas dari gangguan penyakit reproduksi dan minimal memiliki kondisi birahi 3A.

\section{Metode}

Metode yang digunakan dalam penelitian ini adalah percobaan lapang dengan sampel sebanyak 60 ekor sapi PO. Kelompok I: 30 ekor pada sapi yang sama di $\mathrm{IB}$ dengan $(\mathrm{P} 1=$ semen beku dan $\mathrm{P} 2=$ semen cair lama simpan 1 hari), Kelompok II: 30 ekor lainnya pada sapi yang sama di $\mathrm{IB}$ dengan $(\mathrm{P} 3=$ semen beku dan $\mathrm{P} 4=$ semen cair lama simpan 5 hari) yang dilakukan oleh inseminator di desa setempat. Data yang digunakan dalam penelitian ini adalah data primer dan data sekunder. Pengambilan data primer dilakukan dengan cara pengamatan secara langsung (observasi) di lapang yang meliputi berbagai variabel antara lain: jumlah sapi yang digunakan, reproduksi ternak, body condition score (BCS), umur ternak, breed, manajemen peternakan, dan lingkungan. Data sekunder meliputi identitas peternak, tanggal IB, tanggal partus dan riwayat kesehatan ternak berdasarkan hasil wawancara langsung dengan pemilik ternak dan data rekording inseminator.

\section{Variabel pengamatan}

Variabel yang diamati dalam penelitian ini adalah service per conception $(S / C)$, yakni suatu angka yang menunjukkan berapa banyak ternak diinseminasi untuk mendapatkan hasil kebuntingan; Days Open (DO), yaitu lama kosong ternak yang tidak bunting lagi setelah ternak partus; dan Conception Rate $(C R)$, yaitu persentase sapi betina yang bunting pada IB pertama. Untuk membedakan hasil IB dengan menggunakan semen beku dan semen cair dilakukan dengan uji $\mathrm{T}$ berpasangan.

\section{Data pendukung}

Persentase motilitas spermatozoa hari ke-1 dan 5 dengan perlakuan Tris aminomethan $+20 \%$ kuning telur dapat dilihat pada Tabel 1 . 
Tabel 1. Data persentase motilitas spermatozoa hari ke 1 dan 5

\begin{tabular}{cl}
\hline Hari & Rataan \pm SD \\
\hline 1 & $65,25 \pm 1,42$ \\
5 & $53,75 \pm 1,32$ \\
\hline
\end{tabular}

Sumber: Da Costa, Susilawati dan Isnaini (2016)

\section{HASIL DAN PEMBAHASAN}

\section{Service per conception}

Nilai S/C untuk masing-masing

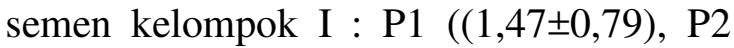
$(1,13 \pm 0,38)$, Kelompok II : P3 $(2,07 \pm 0,64)$ dan P4 $(1,17 \pm 0,38)$. Hasil analisis data uji t berpasangan antara $\mathrm{P} 1$ dengan $\mathrm{P} 2$ dan antara P3 dengan P4 menunjukkan perbedaan sangat nyata terhadap nilai $\mathrm{S} / \mathrm{C}$ $(\mathrm{P}<0,01)$. Nilai $\mathrm{S} / \mathrm{C}$ semen beku memperoleh nilai yang lebih tinggi bila dibandingkan dengan semen cair lama simpan 1 hari dan 5 hari. Hal ini terjadi karena semen beku akan mengalami penurunan fertilitas selama proses pembekuan dan proses thawing yang dilakukan inseminator kurang tepat. Semen cair dengan lama simpan 1 hari memberikan nilai $\mathrm{S} / \mathrm{C}$ yang lebih rendah/baik bila dibandingkan dengan semen cair dengan lama simpan 5 hari. Hal ini disebabkan oleh motilitas semen cair dengan lama simpan 1 hari lebih tinggi yaitu $65,25 \%$ dibandingkan dengan semen cair dengan lama simpan 5 hari $(53,75 \%)$. Semakin lama semen disimpan maka kualitasnya akan semakin turun.

Peternak juga mampu mendeteksi birahi tepat waktu, sehingga IB dilakukan pada waktu yang tepat dan didukung dengan inseminator yang terampil dalam menjalankan IB dan mampu mendeposisikan semen pada 4+. Ihsan dan Wahyuningsih (2011) menyatakan bahwa kisaran normal nilai $\mathrm{S} / \mathrm{C}$ adalah 1,5-2,0. Semakin rendah nilai $\mathrm{S} / \mathrm{C}$ maka semakin bagus tampilan reproduksi ternak betina dan mampu menekan biaya pemeliharaan. Berdasarkan nilai $\mathrm{S} / \mathrm{C}$ yang diperoleh, maka dalam satu kali kebuntingan dibutuhkan 2,07 straw untuk semen beku dan 1,17 straw untuk semen cair.
Iswoyo dan Widiyaningrum (2008) dan (Susilawati, 2013) menyatakan bahwa penyebab tingginya nilai S/C karena : (1) peternak terlambat mendeteksi saat birahi atau terlambat melaporkan sapi birahinya kepada inseminator, (2) adanya kelainan pada alat reproduksi induk sapi, (3) inseminator kurang terampil, (4) fasilitas pelayanan inseminasi yang terbatas, dan (5) kurang lancarnya transportasi. Angka $\mathrm{S} / \mathrm{C} \geq 2$ menunjukkan tingkat reproduksi sapi tersebut kurang efisien sehingga berdampak pada jarak beranak yang lebih lama dan merugikan peternak karena harus mengeluarkan biaya IB lebih banyak.

bahwa inseminator mempunyai pengalaman lebih dari 10 tahun, sehingga keterampilan dalam melakukan IB sangat baik dan mampu mendeposisikan semen pada posisi $4+$. Oleh sebab itu inseminator bukan salah satu faktor tingginya nilai S/C. Semen yang digunakan harus mempunyai PTM minimal $40 \%$ sesuai standar SNI untuk meningkatkan hasil kebuntingan. Semen cair dengan pengencer tris aminomethan $+20 \%$ kuning telur yang disimpan selama 1 dan 5 hari mempunyai motilitas spermatozoa diatas SNI. Spermatozoa yang mempunyai motilitas diatas minimal SNI mampu menurunkan nilai $\mathrm{S} / \mathrm{C}$ di lokasi penelitian.

\section{Days open (DO)}

Nilai DO untuk masing-masing semen, kelompok I: P1 $(102,03 \pm 19,66)$, P2 $(100,43 \pm 32,74), \quad$ Kelompok II: P3 $(110,1 \pm 12,99)$ dan P4 $(103,4 \pm 13,27)$. Analisis Uji t berpasangan menunjukkan bahwa IB menggunakan semen beku dan semen cair tidak terdapat perbedaan yang nyata terhadap DO $(\mathrm{P}>0,05)$. Jumlah penggunaan semen cair ternyata memberikan nilai yang lebih rendah bila 
dibandingkan dengan semen beku dan apabila hasil penelitian ini diterapkan di masyarakat secara luas dan kontinyu akan memberikan dampak yang lebih positif terhadap reproduksi ternak.

Ali et al., (2000) menyatakan bahwa masa kosong tidak ada yang kurang dari 30 hari. Hal ini diperkuat oleh pernyataan Stevenson (2001) bahwa masa kosong untuk ternak yang baik adalah 4060 hari setelah partus. Hasil penelitian Izquierdo et al., (2008) menyatakan bahwa rata-rata masa kosong yang terjadi pada ternak adalah 85-115 hari setelah partus. Hasil penelitian yang diperoleh masih lebih rendah bila dibandingkan dengan hasil penelitian Nuryadi dan Wahyuningsih (2011) bahwa DO sapi PO yaitu $130,27 \pm 20,99$ hari. Setelah dilakukan evaluasi di lapang, lama kosong yang panjang diakibatkan karena pakan yang diberikan pada ternak hanya berasal dari limbah pertanian seperti jerami, tebon jagung dan rumput gajah tanpa ada tambahan pakan konsentrat. Selain itu, hanya bekatul yang ditambahkan pada air minum. Cara ini hanya dilakukan oleh beberapa peternak dan sebagian besar pemberian minum hanya dengan air biasa. Nutrisi dalam pakan merupakan faktor penting yang harus dipenuhi untuk kehidupan pokok dan kebutuhan.

Pemberian pakan dilakukan 3-4 kali/hari dengan rata-rata kuantitas hijauan yang diberikan sebanyak 38,33 $\pm 19,69$ $\mathrm{kg} / \mathrm{ekor} / \mathrm{hari}$. Pemberian pakan di lokasi penelitian masih lebih rendah bila dibandingkan dengan hasil penelitian Wahyudi dkk., (2014) bahwa berdasarkan penimbangan pakan yang diberikan di lokasi penelitian dapat diketahui kuantitas hijauan yang diberikan rata-rata sebesar $43 \pm 6,16 \mathrm{~kg} / \mathrm{ekor} /$ hari dan konsentratnya

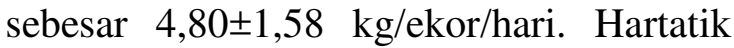
dkk., (2009) menyatakan bahwa pemberian pakan yang kualitasnya kurang bagus dan jumlah pemberiannya kurang, bisa mengganggu proses reproduksi sehingga mengakibatkan kawin berulang, nilai S/C tinggi, DO yang lebih lama dan CI yang panjang. Masa kosong yang panjang juga disebabkan karena para peternak tidak mengawinkan sapinya sebelum pedet disapih, lama penyapihan 3-4 bulan akan mempengaruhi nilai DO yang semakin panjang. Tujuan peternak melakukan hal ini untuk menghindari kawin berulang.

Faktor lain yang mempengaruhi lama DO adalah bangsa dan keadaan musim. Bangsa ternak sapi PO di lokasi penelitian masih memiliki masa kosong yang panjang dan melebihi batas ideal. Nuryadi dan Wahyuningsih (2011) menyatakan bahwa sapi PO memiliki masa kosong yang lebih rendah dibandingkan dengan bangsa sapi peranakan Limousin. Hal ini dapat dilihat dari hasil analisis statistik yang memperlihatkan nilai DO sapi PO 130,27 $\pm 20,99$ hari dan sapi peranakan Limousin 149,32 $\pm 24,19$ hari. Pengaruh musim sangat menentukan ketersedian pakan, pada musim penghujan ketersediaan pakan lebih melimpah dibandingkan dengan musim kemarau. Kenyataan di lokasi penelitian pada musim kemarau panjang, tingkat kebuntingan lebih rendah dibandingkan dengan musim penghujan. Hal ini terjadi karena ketersediaan pakan yang kurang akan mempengengaruhi jumlah pakan yang dikonsumsi ternak dimana semakin rendah nutrisi dalam pakan dapat menurunkan nilai produktivitas ternak. Menurut Taufik and Suriyasataphorn (2008), sapi di musim hujan dan musim dingin memiliki peluang kebuntingan yang lebih tinggi dibandingkan dengan musim panas, walaupun hasilnya tidak signifikan.

\section{Conception rate}

Kelompok I menunjukkan CR semen beku (P1) sebesar 63,33\%, semen cair dengan penyimpanan 1 hari (P2) sebesar 86,67\%. kelompok II, CR pada hasil IB menggunakan semen beku (P3) sebesar 16,67 \% dan menggunakan semen cair dengan penyimpanan 5 hari (P4) sebesar $83,33 \%$.

Nilai CR semen beku lebih rendah bila dibandingkan dengan semen cair 
dengan lama simpan 1 dan 5 hari. Hal ini disebabkan oleh kualitas semen beku mengalami penurunan selama proses pembekuan. Semen yang sudah dibekukan menghadapi beberapa masalah yaitu kurang lebih $30 \%$ spermatozoa mati selama pembekuan dan spermatozoa yang bertahan hidup mempunyai fertilitas yang lebih rendah. Penggunaan semen beku menghasilkan persentase kebuntingan yang lebih rendah bila dibandingkan dengan semen cair, dimana semakin tinggi kualitas semen akan mempengaruhi tingkat kebuntingan ternak.

Faktor lain yang mempengaruhi rendahnya nilai $\mathrm{CR}$ pada semen beku adalah proses thawing yang dilakukan inseminator harus diperhatikan, karena thawing dapat menurunkan motilitas spermatozoa. Thawing yang dilakukan inseminator dilokasi penelitian yaitu dengan menggunakan air sumur atau air biasa yang mempunyai kisaran suhu $25^{\circ} \mathrm{C}$. Proses thawing seperti ini dapat menurunkan kualitas semen. Thawing yang baik dan dianjurkan adalah pada air hangat yang bersuhu $36-37^{\circ} \mathrm{C}$ selama $15-30$ detik. Hasil penelitian Utami dan Tophianong (2014) menyatakan bahwa semen beku setelah thawing dalam air $37^{\circ} \mathrm{C}$ memiliki kecenderungan menghasilkan motilitas yang lebih tinggi jika dibandingkan dengan dalam air $8^{0} \mathrm{C}$. Hal ini menunjukkan bahwa bila suhu thawing semakin rendah dan durasi thawing panjang menyebabkan penurunan motilitas spermatozoa. Selain itu, suhu thawing $37^{\circ} \mathrm{C}$ yang digunakan sesuai dengan suhu ideal bagi aktivitas spermatozoa, sehingga persentase spermatozoa motil terlihat lebih tinggi. Arifianti dkk., (2008) menyatakaan bahwa rendahnya nilai $\mathrm{CR}$ hasil IB dengan semen beku disebabkan oleh kurangnya jumlah spermatozoa motil.

\section{KESIMPULAN}

\section{Kesimpulan}

Keberhasilan IB menggunakan semen cair dengan pengencer tris aminomethan $+20 \%$ kuning telur lebih baik dengan penyimpanan 1 hari dan 5 hari dibandingkan menggunakan semen beku.

\section{Ucapan terimakasih}

Peneliti mengucapkan terima kasih kepada Loka penelitian sapi potong Grati, inseminator, dan peternak sapi di Kecamatan Grati yang telah memberikan fasilitas penelitian.

\section{DAFTAR PUSTAKA}

Ali, A. K. A., A. Al-Haidary, M. H. Alshaikh, Gamil, and E. Hayes. 2000. Effect of days open on the lactation curve of holstein cattle in Saudi Arabia. Journal Animal Science. 7 (4): 288-298.

Arifianti, R. I., B. Purwantara, T. L. Yusuf, D. Sajuthi, dan Amrozi. 2008. Angka konsepsi hasil inseminasi semen cair versus semen beku pada kuda yang disinkronisasi estrus dan ovulasi. Media Peternakan. 33 (1): 3

Da Costa, N., Susilawati dan Isnaini. 2016. Kualitas semen sapi Peranakan Ongole (PO) selama pendinginan menggunakan pengencer yang berbeda. Jurnal Ilmu-Ilmu peternakan. 12(1): 53-62

Direktorat Jenderal Peternakan, Departemen Pertanian. 2007. Strategi pengembangan peternakan di Indonesia pada milenium ketiga: Kebijakan Bidang Kesehatan Hewan: 90-03.

Hartatik, T., D. A. Mahardika, T. S. M., Widi, dan E. Baliarti. 2009. Karakteristik dan kinerja induk sapi silangan Limousin-Madura dan Madura di Kabupaten Sumenep dan Pamekasan. Buletin Peternakan. 33 (3): 143-147.

Ihsan, M. N., dan S. Wahyuningsih. 2011. Penampilan reproduksi sapi potong di Kabupaten Bojonegoro. Jurnal Ternak Tropika. 12 (2):7680. 
Iswoyo dan Widiyaningrum, P. 2008.

Performans reproduksi sapi Peranakan Simmental (PSM) hasil inseminasi buatan di Kabupaten Sukoharjo Jawa Tengah. Jurnal Ilmiah Ilmu-Ilmu Peternakan. 11 (3): 125-133.

Izquierdo, C. A., S. D. P. Betancurt, V. M. X. Campos, C. G. R. Lang, A. C. Jimenez, M. S. C. Jimenez, J. E. G. Liera, dan J. A. S. Oaxaca, S. C. Suares. 2008. Effect of the offsprings sex on open days in dairy cattle. Journal Animal Veteriner.7 (10): 1329-1d331.

Kementerian Pertanian Badan Pusat Statistik. 2011. Rilis hasil akhir PSPK 2011:3.

Nuryadi dan Wahjuningsih, S. 2011. Penampilan reproduksi sapi Peranakan Ongole dan Peranakan Limousin di Kabupaten Malang. Jurnal Ternak Tropika 12 (1): 7681.

Situmorang, P. 2002. Pengaruh kolesterol terhadap daya hidup dan fertilitas spermatozoa sapi. Jurnal Ilmu Ternak Dan Veteriner. 7 (4): 251258.
Susilawati, T. 2011. Spermatology. Universitas Brawijaya (UB) Press. Malang

Susilawati, T. 2013. Pedoman inseminasi buatan pada ternak. Universitas Barwijaya (UB) Press. Malang. ISBN 978-602-203-458-2.

Stevenson, J. S. 2001. Reproductive management of dairy cows in high milk-producing herds. Jurnal Dairy Science. 84 (2): 128-143.

Taufik and Suriyasataphorn. 2008. Survival analysis of the effect of season at calving, lactation number and breeding on days open in dairy cattle. Jurnal Ilmu Ternak dan Veteriner. 13 (3): 214220.

Utami, T. dan T. C. Topianong. 2014. Pengaruh suhu thawing pada kualitas spermatozoa sapi pejantan. Jurnal sains veteriner. 32(1). ISSN: 0126-042.

Wahyudi, L., T. Susilawati.dan N. Isnaini. 2014. Tampilan reproduksi hasil inseminasi buatan menggunakan semen beku hasil sexing pada sapi Persilangan Ongole di peternakan rakyat. Jurnal Ternak Tropika 15 (1): 80-88. 